\title{
(a) OPEN ACCESS \\ Decreasing cerebral palsy prevalence in multiple births in the modern era: a population cohort study of European data
}

Oliver Perra, ${ }^{1}$ Judith Rankin, ${ }^{2}$ Mary Jane Platt, ${ }^{3}$ Elodie Sellier ${ }_{1}^{4,5}$ Catherine Arnaud ${ }_{1}^{6,7}$
Javier De La Cruz, ${ }^{8}$ Ingeborg Krägeloh-Mann, ${ }^{9}$ David G Sweet, ${ }^{10}$ Solveig Bjellmo ${ }^{11,12}$

\section{ABSTRACT}

published online only. To view please visit the journal online (http://dx.doi.org/10.1136/ archdischild-2020-318950).

For numbered affiliations see end of article.

\section{Correspondence to} Dr Oliver Perra, School of Nursing and Midwifery; Centre for Evidence and Social Innovation, Queen's University Belfast, Belfast BT9 7LB, UK; o.perra@qub.ac.uk

Received 31 January 2020

Revised 26 May 2020

Accepted 15 June 2020

Published Online First

26 August 2020

Participants 4446125 single and multiple live births,
Multiple births (twins or higher order multiples) are increasing in developed countries and may present higher risk for cerebral palsy (CP). However, few studies can reliably investigate trends over time because these outcomes are relatively rare.

Objective We pooled data from European CP registers to investigate $C P$ birth prevalence and its trends among single and multiple births born between 1990 and 2008 . Design Population cohort study.

Setting 12 population-based registers from the

Surveillance of Cerebral Palsy in Europe collaboration. of whom $8416(0.19 \%)$ had CP of prenatal or perinatal origin.

Main outcomes CP diagnosis ascertained in childhood using harmonised methods; CP subtype; Motor impairment severity among CP cases.

Results The rate of multiple births increased from 1990 Multiples displayed higher risk for CP $(R R=4.27,95 \% \mathrm{Cl}$ 4.00 to 4.57$)$. For singletons and multiples alike, risk for $\mathrm{CP}$ was higher among births of lower gestational age (GA) or birth weight (BW). However, CP birth prevalence declined significantly among very preterm ( $<32$ weeks) and very low BW $(<1500 \mathrm{~g})$ multiples. Singletons and multiples with CP displayed similar severity of motor impairment.

Conclusions Between 1990 and 2008, CP birth prevalence decreased steadily among multiples with low GA or BW. Furthermore, multiples with CP display similar profiles of severe motor impairment compared with CP singletons. Improvements in management of preterm birth since the 1990s may also have been responsible for providing better prospects for multiples.

\section{INTRODUCTION}

The rate of multiple births in developed countries ${ }^{1-6}$ has risen in the last four decades. Studies ${ }^{7-11}$ report that multiple births are associated with increased risk for cerebral palsy (CP), defined as lifetime physical disabilities due to non-progressive injuries to the immature or developing brain. ${ }^{12-14}$ Twins and higher order multiples are more likely to be born before term ${ }^{1}$ and to present low birth weight (LBW); $;^{15}$ prematurity and LBW are, in turn, significant risk factors for $\mathrm{CP}:{ }^{16}$ thus, increased rates of multiple births might expose more newborns to risk for CP. ${ }^{17}$ However, European-wide data ${ }^{18}$ suggest that the prevalence of CP has declined between birth years 1980 and 2003, particularly among

\section{What is already known on this topic?}

- The rate of multiple births is increasing, and multiple births are at higher risk for cerebral palsy (CP). However, changes in obstetric practice since the 1990s may have impacted on risk for CP among preterm and low birth weight multiples.

- Multiple births and CP are relatively rare events: their study necessitates pooling of data from different centres and countries.

\section{What this study adds?}

Multiples remain at higher risk for $\mathrm{CP}$, but this risk has been decreasing steadily since the 1990 s among very preterm or low birth weight multiples.

- Singleton and multiple births with CP display similar severity of motor impairment.

- Advances in obstetric care may be responsible for these changes in CP risk among multiples.

very and moderate LBW infants. Improvements in neonatal care responsible for these trends may also have impacted on risk among multiple births. An analysis of recent trends in CP prevalence among multiple births is timely.

We investigated the birth prevalence of CP among single and multiple births born between 1990 and 2008 using data collected by the multicentre Surveillance of Cerebral Palsy in Europe (SCPE): by harmonising definitions and methods, this collaboration provides a reliable source of data on CP prevalence. Topp and colleagues ${ }^{10}$ analysed data from SCPE cohorts until 1990: in our study, we analyse trends in births between 1990 and 2008 to investigate cohorts born in the antenatal corticosteroids $^{19}$ and surfactant ${ }^{20}$ era. A diagnosis of CP can only be confirmed reliably in childhood: ${ }^{21}$ data on children with ascertained CP were available up to birth year 2008 at the time of analyses.

Topp and colleagues ${ }^{10}$ reported a higher proportion of second-born twins among twins with $\mathrm{CP}$ and suggested that this may indicate risks for intrapartum asphyxia of the second-born twin during a vaginal delivery. A different study ${ }^{8}$ on USA and Australia populations did not confirm differences in 
risk for $\mathrm{CP}$ associated with twins' birth order. Investigating the order of birth of twins across different types of birth may help clarify this issue.

Our main aim was to investigate changes in risk for CP among multiple births. For this purpose, we analysed trends in CP prevalence by categories of gestational age (GA) and birth weight (BW). Our objectives were to:

1. Investigate prevalence of $\mathrm{CP}$ over time in multiples and singletons overall, and across GA and BW categories;

2. Compare CP type and severity of impairment between multiples and singletons with CP;

3. Investigate associations between mode of delivery and birth order of twins with CP.

\section{METHODS}

\section{Study design}

A population cohort study: population-based registers participating to SCPE provided information on children with CP, as well as denominators (total live births) by type of birth (single versus multiple) and by GA and BW categories in their catchment area. Some of these registers cover entire countries, while others cover defined areas within countries.

\section{Participants}

$\mathrm{CP}$ is a group of permanent disorders of movement and/or posture caused by non-progressive interferences/lesions to or abnormalities of the developing brain. ${ }^{12}{ }^{14}$ SCPE registers use a range of sources for the notification and diagnostic ascertainment of eligible participants. Children with a postneonatal onset of CP were excluded from the CP population. ${ }^{22}$ Methods used by participating registers are detailed elsewhere. ${ }^{1423}$

\section{Setting}

Overall, 23 population-based registers provided data for births between 1 January 1990 and 31 December 2008. A diagnosis of $\mathrm{CP}$ is reliable in later childhood: ${ }^{21}$ SCPE registers confirm CP diagnoses after age 4 years, with the exception of deaths that take place before a suspected diagnosis is confirmed (age 2-4 years). The age when registers consider ascertainment of $\mathrm{CP}$ diagnoses complete varies across countries, but it takes place by the time children are of primary education age. At the time of analyses, data were available for children born until 2008 .

In order to capture changes over time, we stipulated that centres had to provide information on CP and multiple and single births denominators by GA or BW categories for at least 3 years: data from 11 centres were excluded for not providing this information (see online supplementary appendix 1). Overall, 12 centres were included in the analyses: 2 provided only denominators on multiple births by BW and are thus excluded in prevalence analyses stratified by GA. The number of births by centre and birth type are reported in table 1.

\section{Variables}

CP subtypes were classified as unilateral spastic, bilateral spastic, dyskinetic and ataxic. ${ }^{22}$

The Gross Motor Function Classification System (GMFCS) provided a reliable assessment of children's severity of motor impairment. ${ }^{24} 25$ However, some SCPE registers adopted this measure later than others. To avoid missing data and provide a meaningful measure of Severity of Motor Impairment, we categorised individuals with moderate-severe impairment to those with GMFCS level III to V or who were not able to walk without assistive devices.
Table 1 Number of children with CP, multiples with CP, live births, multiple live births and number of cohort birth years for which data were available by register

\begin{tabular}{|c|c|c|c|c|c|}
\hline Register & N CP & $\begin{array}{l}\text { Multiples } \\
\text { CP }\end{array}$ & Live births & $\begin{array}{l}\text { Multiple } \\
\text { live births }\end{array}$ & $\begin{array}{l}\text { Cohort birth } \\
\text { years }\end{array}$ \\
\hline $\begin{array}{l}\text { Cork \& Kerry, } \\
\text { Ireland }\end{array}$ & 127 & 26 & 82019 & 2204 & 9 \\
\hline $\begin{array}{l}\text { Gothenburg, } \\
\text { Sweden }\end{array}$ & 835 & 98 & 421050 & 12229 & 19 \\
\hline NW England, UK & 1153 & 106 & 534316 & 14167 & 16 \\
\hline Oxford, UK & 737 & 84 & 483734 & 15014 & 14 \\
\hline Denmark & 2106 & 263 & 1029591 & 39613 & 18 \\
\hline Viterbo, Italy & 142 & 14 & 37886 & 751 & 18 \\
\hline Norway & 1257 & 158 & 638888 & 22556 & 10 \\
\hline Madrid, Spain & 79 & 15 & 54851 & 1180 & 9 \\
\hline Slovenia & 309 & 45 & 142311 & 4651 & 8 \\
\hline Portugal & 1440 & 150 & 871439 & 22583 & 8 \\
\hline Latvia & 93 & 4 & 61210 & 1418 & 9 \\
\hline Hungary & 138 & 15 & 88830 & 2883 & 9 \\
\hline
\end{tabular}

$\mathrm{CP}$, cerebral palsy.

In analyses that involved only children with $\mathrm{CP}$ and their outcomes we controlled for GA and BW: to differentiate between low BW because of prematurity and small for gestation age, CP children were assigned a Standardised BW $z$ Score to indicate deviation from the expected weight for their GA and sex. BW norms were different for singletons and multiples (see online supplementary appendix 2).

\section{Statistical analysis}

CP prevalence is reported per 1000 live births. CP prevalence across multiples and singletons is compared using risk ratios (RR).

We analysed trends over time using multilevel Negative Binomial models whereby observations were nested within registers. Multilevel models allow controlling for heterogeneity across registers (see online supplementary appendix 3). Models were adjusted for offset terms to account for differences in the number of live births across registers' catchment areas. Time trends described changes in prevalence year by year. We investigated linear and non-linear (quadratic) trends, and tested nested models using likelihood-ratio $\chi^{2}$ tests with a threshold of $\mathrm{p}<0.005$. Coefficients reported are incidence rate ratios (IRR).

In analyses of outcomes among children with CP, we used multilevel logistic regressions to model associations between the outcome and birth type, successively adding covariates GA category and BW $z$ scores (see online supplementary appendix 3 ). Whether the CP birth was single or multiple was unknown for 272 cases $(3.23 \%)$, who were excluded from analyses: sensitivity analyses were run assigning unknown births to singletons and then to multiples, which replicated the patterns of results presented.

\section{RESULTS}

\section{Multiple births and CP}

Results indicated an increase of multiple births over time that followed a quadratic trend: $2.47 \%$ of total births were multiples in 1990 , increasing to $3.34 \%$ in 2000 , and a successive deceleration (eg, 2.76\% in 2008): trends differed across centres (see online supplementary appendix 4).

The overall prevalence of CP cases per 1000 live births among singletons was 1.64 (95\% CI 1.60 to 1.68$)$, but was $7.02 \mathrm{CP}$ 
Table 2A Multilevel negative binomial regression coefficients of the total number of CP births on total live births by singletons and multiples

\begin{tabular}{lllll}
\hline Model parameters & Singletons & $95 \% \mathrm{Cl}$ & Multiples & $95 \% \mathrm{Cl}$ \\
\hline Intercept & 0.002 & 0.001 to 0.003 & 0.010 & 0.001 to 0.013 \\
Yearly rate of change & 0.976 & 0.952 to 1.001 & 0.972 & 0.955 to 0.990 \\
$\begin{array}{l}\text { Overdispersion: Ln(Alpha) } \\
\text { Between-centre variation }\end{array}$ & -5.691 & -7.332 to -4.049 & -3.008 & -4.039 to -1.977 \\
$\begin{array}{l}\text { Initial status } \\
\text { Rate of change }\end{array}$ & 0.239 & 0.092 to 0.621 & 0.042 & 0.006 to 0.288 \\
Covariance & 0.002 & 0.001 to 0.004 & NA & \\
Model fit & -0.017 & -0.035 to 0.001 & NA & \\
\hline
\end{tabular}

Parameters in bold are significant at $p<0.005$. Comparisons of models using the likelihood ratio test indicated that estimating centre-level variance around the rate of change and the covariance between intercept and rate of change of Multiples did not improve model fit (at $p<0.005$ ). Therefore, these terms were not modelled.

cases per 1000 live births among multiples (95\% CI 6.58 to 7.48): risk ratio $(\mathrm{RR})=4.27,95 \% \mathrm{CI} 4.00$ to 4.57 . We report $\mathrm{CP}$ prevalence trends across singletons and multiples in table $2 \mathrm{~A}$ : these indicated a non-significant linear decrease in prevalence among singletons $(\mathrm{IRR}=0.98)$, while a linear decrease among multiples $(\mathrm{IRR}=0.97)$ was significant.

\section{Prevalence of CP by multiple birth and GA}

Results between birth years 1990-2008 did not indicate substantial differences across singletons and multiples born extremely or very preterm ( $<32$ weeks), RR $=0.97 \quad(95 \%$ CI 0.86 to 1.08 ) or between singletons and multiples born moderately preterm (32-36 weeks), $\mathrm{RR}=0.96$ (95\% CI 0.82 to 1.11 ) (see table $2 \mathrm{~B}$ ). However, full-term multiples displayed higher risk for CP compared with full-term singletons, $\mathrm{RR}=1.89$ (95\% CI 1.56 to 2.30$)$.

Significant decreases in the prevalence of CP were revealed for singletons and multiples born less than 32 weeks GA and among singletons born 32-36 weeks GA (see figure 1 and table 3). Prevalence of CP remained stable for multiples born 32-36 weeks GA and did not change significantly for full-term singletons or full-term multiples (see also online supplementary appendix 5).

\section{Prevalence of CP by multiple birth and BW}

The prevalence of CP between 1990 and 2008 was similar for singletons and multiples born weighing less than $1500 \mathrm{~g}$, $\mathrm{RR}=0.95$ (95\% CI 0.85 to 1.05 ). The prevalence of CP was higher among singletons born weighing between 1500 and less than $2500 \mathrm{~g}$ when compared with multiples of the same BW, $\mathrm{RR}=0.79$ (95\% CI 0.70 to 0.88 ). In contrast, multiples born
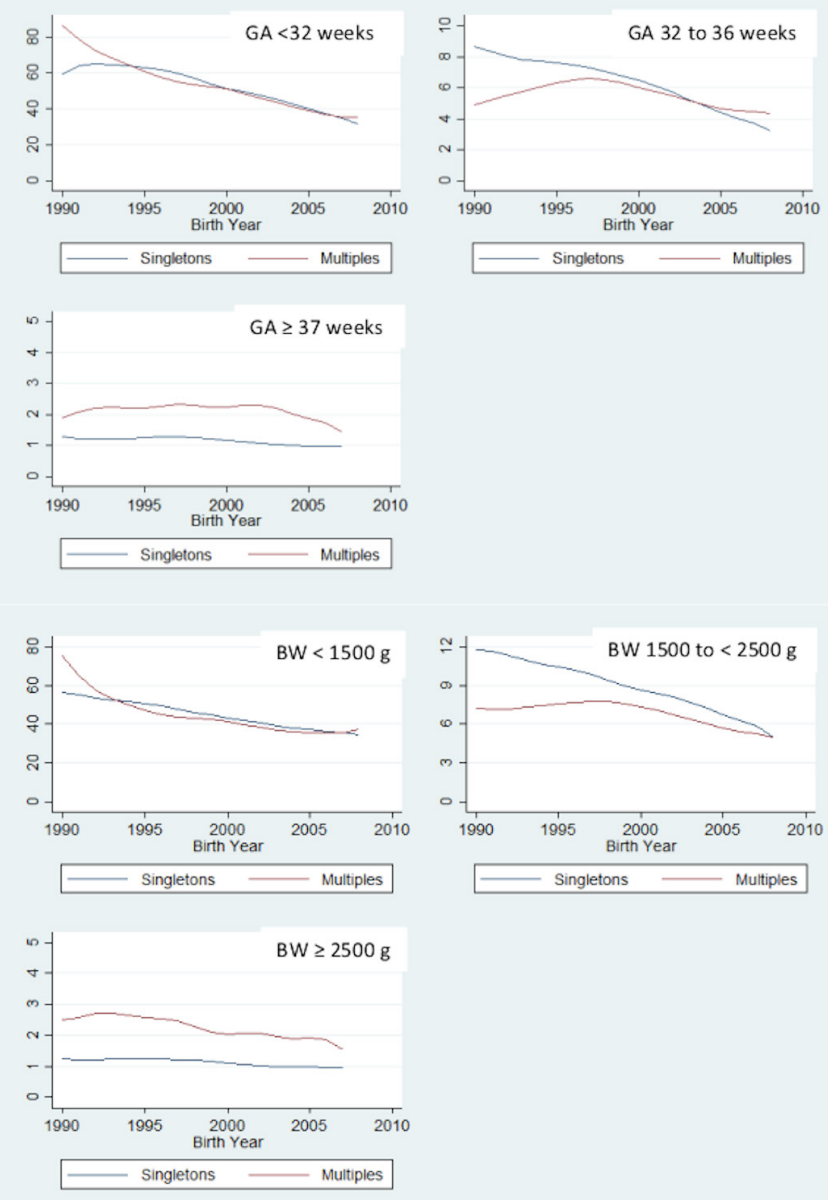

Figure 1 Prevalence of cerebral palsy across singletons and multiples by year and by categories of GA and BW. Raw trends over time are represented by smoothed curves, estimated using locally weighted scatterplot smoothing. BW, birth weight; GA, gestational age.

with normal BW $(\geq 2500 \mathrm{~g})$ displayed a higher risk for CP compared with normal BW singletons, $\mathrm{RR}=1.92$, (95\% CI 1.61 to 2.30) (see table 2B).

A linear decrease in CP prevalence was observed for both very LBW singletons and multiples and among moderately LBW singletons, but not among moderately LBW multiples (see figure 1 and table 3 ). No significant changes across time were observed among normal BW singletons or normal BW multiples (see online supplementary file 1).

\begin{tabular}{|c|c|c|c|c|c|c|}
\hline & Singletons & $95 \% \mathrm{Cl}$ & Multiples & $95 \% \mathrm{Cl}$ & RR & $95 \% \mathrm{Cl}$ \\
\hline \multicolumn{7}{|l|}{ Gestational age } \\
\hline$<32$ weeks & 47.35 & 44.50 to 50.34 & 45.84 & 41.43 to 50.60 & 0.97 & 0.86 to 1.08 \\
\hline $32-36$ weeks & 5.47 & 5.09 to 5.87 & 5.24 & 4.56 to 5.99 & 0.96 & 0.82 to 1.11 \\
\hline \multicolumn{7}{|l|}{ Birth weight } \\
\hline $37+$ weeks & 1.07 & 1.03 to 1.11 & 2.02 & 1.65 to 2.45 & 1.89 & 1.56 to 2.30 \\
\hline$<1500 \mathrm{~g}$ & 42.79 & 40.37 to 45.32 & 40.48 & 36.76 to 44.47 & 0.95 & 0.85 to 1.05 \\
\hline $1500-2499 \mathrm{~g}$ & 8.37 & 7.92 to 8.83 & 6.58 & 5.90 to 7.31 & 0.79 & 0.70 to 0.88 \\
\hline $2500+g$ & 1.07 & 1.03 to 1.10 & 2.05 & 1.71 to 2.44 & 1.92 & 1.61 to 2.30 \\
\hline
\end{tabular}

RRs represent the CP risk of multiples compared with singletons. Parameters in bold are significant at $p<0.005$ 
Table 3 IRRs indicating yearly changes in the total number of CP cases on the total number of live births, by GA or BW categories and by singletons or multiples

\begin{tabular}{|c|c|c|c|c|c|c|c|c|c|c|}
\hline & Singletons & IRR & $95 \% \mathrm{Cl}$ & Model Wald $\chi^{2}$ & $\begin{array}{l}\text { Cross-centre } \\
\text { variability in } \\
\text { slope? }\end{array}$ & Multiples & IRR & $95 \% \mathrm{Cl}$ & Model Wald $\chi^{2}$ & $\begin{array}{l}\text { Cross-centre } \\
\text { variability in } \\
\text { slope? }\end{array}$ \\
\hline \multicolumn{11}{|l|}{$\mathrm{GA}$} \\
\hline$<32$ weeks & Linear yearly decrease & $0.96^{*}$ & 0.95 to 0.98 & $\chi^{2}(1)=21.38^{*}$ & No & Linear yearly decrease & $0.95^{*}$ & 0.93 to 0.98 & $\chi^{2}(1)=14.62^{*}$ & No \\
\hline $32-36$ weeks & Linear yearly decrease & $0.96^{*}$ & 0.94 to 0.98 & $\chi^{2}(1)=17.50^{*}$ & No & No yearly change & 0.99 & 0.96 to 1.03 & $\chi^{2}(1)=0.10$ & No \\
\hline $37+$ weeks & No yearly change & 0.99 & 0.96 to 1.02 & $\chi^{2}(1)=0.29$ & Yes & No yearly change & 0.98 & 0.94 to 1.02 & $\chi^{2}(1)=0.77$ & No \\
\hline \multicolumn{11}{|l|}{ BW } \\
\hline$<1500 \mathrm{~g}$ & Linear yearly decrease & $0.96^{*}$ & 0.95 to 0.98 & $\chi^{2}(1)=20.87^{*}$ & No & Linear yearly decrease & $0.95^{*}$ & 0.93 to 0.97 & $\chi^{2}(1)=19.87^{*}$ & No \\
\hline $1500-<2500 \mathrm{~g}$ & Linear yearly decrease & $0.97^{*}$ & 0.96 to 0.98 & $\chi^{2}(1)=18.88^{*}$ & No & No yearly change & 0.99 & 0.96 to 1.01 & $\chi^{2}(1)=0.73$ & No \\
\hline$\geq 2500 \mathrm{~g}$ & No yearly change & 0.98 & 0.95 to 1.01 & $\chi^{2}(1)=1.08$ & Yes & No yearly change & 0.96 & 0.92 to 1.00 & $\chi^{2}(1)=4.01$ & No \\
\hline
\end{tabular}

We also reported whether the models indicated cross-centre variability in the rate of change (slope) of CP prevalence. IRRs were estimated using multilevel negative binomial regressions. Parameters of the models are introduced in online supplementary appendix 4 and full parameters reported in online supplementary appendices 5 and 6 . Cross-centre variability in slope indicated that different centres displayed varying rates of change in the CP prevalence for that category of birth and GA or BW. Conversely, if no cross-centre variability was observed, the rate of change of CP prevalence was estimated to be consistent across centres. The lack of significant cross-centre variability in the slopes of CP prevalence for singletons and multiples in lower GA and BW categories indicated that the significant decrease of CP cases among these at-risk categories was consistent across centres.

${ }^{*} \mathrm{P}<0.005$.

$\mathrm{BW}$, birth weight; $\mathrm{CP}$, cerebral palsy; GA, gestation age; IRR, incidence rate ratios.

\section{Differences in CP type and motor impairment}

A higher percentage of multiples met criteria for spastic bilateral CP (see table 4) and displayed higher odds of presenting this subtype rather than other subtypes, adjusted $\mathrm{OR}=1.39(95 \% \mathrm{CI}$ 1.21 to 1.61): ORs were adjusted for birth year and centre-level effects. However, these differences were non-significant once we controlled for variations in GA and BW $\mathrm{z}$ scores: adjusted $\mathrm{OR}=0.87$ for multiples compared with singletons (95\% CI 0.74 to 1.01). Compared with full-term birth, birth before 32 weeks was associated with a threefold increase in the odds of spastic bilateral CP, OR=3.16 (95\% CI 2.80 to 3.56). Higher BW for GA was also associated with reduced odds of spastic bilateral CP, $\mathrm{OR}=0.95$ (95\% CI 0.93 to 0.98$)$.

The percentage of singletons and multiples with moderatesevere motor impairment was $43 \%$ in both cases: $(n=2975 / 6880)$ and $(n=402 / 941)$, respectively. Models (see online supplementary appendix 7) indicated a linear decrease in the odds of moderate-severe impairment $(\mathrm{OR}=0.98,95 \% \mathrm{CI} 0.97$ to $0.99)$, but an interaction term suggested this trend did not differ between singletons and multiples, LR test $\chi^{2}(1)=0.26, p=0.61$.

\section{$\mathrm{CP}$ risk and birth order}

Twin children with CP did not display different birth order: $50.39 \%(\mathrm{n}=384 / 762)$ were second-born (binomial test assuming equal probability of being first-born or second-born: $p=0.86$ ). A higher proportion of twins with CP born by vaginal delivery was first-born rather than second-born: $55.39 \%(n=113 / 204)$. The proportion of first-born and second-born CP twins did not differ

\begin{tabular}{|c|c|c|c|c|}
\hline & & Singletons & Multiples & Total \\
\hline \multirow[t]{2}{*}{ Spastic bilateral } & $\mathrm{N}$ & 3610 & 570 & 4180 \\
\hline & $\%$ & 50.38 & 58.28 & 51.33 \\
\hline \multirow[t]{2}{*}{ Spastic unilateral } & $\mathrm{N}$ & 2471 & 309 & 2780 \\
\hline & $\%$ & 34.48 & 31.60 & 34.14 \\
\hline \multirow[t]{2}{*}{ Other CP type } & $\mathrm{N}$ & 929 & 80 & 1009 \\
\hline & $\%$ & 12.96 & 8.18 & 12.39 \\
\hline \multirow[t]{2}{*}{ CP type uncertain } & $\mathrm{N}$ & 156 & 19 & 175 \\
\hline & $\%$ & 2.18 & 1.94 & 2.15 \\
\hline
\end{tabular}

Pearson $\chi^{2}(3)=28.70, p<0.001$.

$\mathrm{CP}$, cerebral palsy. significantly among emergency caesarean deliveries, $47.57 \%$ being first born $(n=98 / 206)$.

\section{DISCUSSION}

We investigated the prevalence of CP in multiples and singletons using population-based data collated from a European collaboration. By harmonising methods and definitions, and by adopting robust procedures for ascertainment, this collaboration provides reliable data on the condition over time. The results indicate that multiple births had been increasing since 1990, and they were associated with increased risk for CP. This increased risk was related to the higher prevalence of preterm or LBW births among multiples, which was also underlined by the finding that multiples with CP displayed the bilateral spastic CP-subtype typical of lower GA and BW groups. Despite multiples being at increased risk for CP, CP prevalence decreased linearly among multiples in at-risk categories because of prematurity and LBW.

In particular, while CP prevalence among multiples born less than 32 weeks was higher for cohorts born in the early 1990s, this declined significantly, becoming comparable to the CP prevalence among singletons of the same GA (see figure 1). A significant decline in CP prevalence was also observed among multiples weighing less than $1500 \mathrm{~g}$ (LBW). Results based on SCPE data indicated an analogous decline in CP prevalence among LBW European children: ${ }^{18}$ here, we show that this decline involves both multiples and singletons. Furthermore, the decline in $\mathrm{CP}$ prevalence among the lowest GA and BW categories of singletons and multiples was consistent across participating registers (see table 3): this has potential clinical significance (see online supplementary file 1 ).

The higher risk for CP among singletons in the Moderate LBW category $(1500-2499 \mathrm{~g})$ is consistent with findings from another large population study: ${ }^{8}$ however, our findings also show that this difference has been narrowing over time.

In contrast, $\mathrm{CP}$ prevalence among multiples born at term did not change significantly between 1990 and 2008. Overall, 2.02 per 1000 full-term multiples births were diagnosed with $\mathrm{CP}$, which is substantially higher than the prevalence of 1.07 per 1000 births among full-term singletons. A specific pathogenic mechanism may be suspected for CP in full-term multiples. Some research suggests a role for intrapartum risks, for example, twintwin transfusion syndrome. ${ }^{8}$ Other studies provided evidence of intrauterine growth divergence being associated with increasing risk for $\mathrm{CP}:{ }^{2627}$ since growth divergence is a common occurrence 
in multiple pregnancies, ${ }^{8}$ this may be a key factor in determining differential patterns of risk between singletons and multiples, particularly when the pregnancy reaches term.

Among children with CP, multiples and singletons displayed similar profiles of motor impairment severity. Furthermore, we report a significant linear decrease in the proportion of the $\mathrm{CP}$ population with moderate-severe motor impairment that did not vary significantly between singletons and multiples. Improvements in care that have contributed to an overall decrease of moderate-severe $\mathrm{CP}$ across European countries ${ }^{18}$ may have also reduced risk for severe impairment among multiples.

Results did not indicate a higher proportion of second-born among twins with $\mathrm{CP}$, and when considering those twins born by vaginal delivery, second-born twins were proportionally fewer $(45 \%)$. If intrapartum asphyxia could explain CP risk of secondborn twins in cohorts before the $1990 \mathrm{~s}^{28}$ our results suggest that changes in obstetric care since 1990 have countered this pathogenic mechanism.

Our findings were limited by our inability to investigate trends in birth years after 2008: this is due to the need for reliable $\mathrm{CP}$ ascertainment by registers. Furthermore, many variables that could inform about potential causal mechanisms linking multiple birth and $\mathrm{CP}$ were not reported. For example, a causal pathway may involve increased risk for placental abruption in multiple births ${ }^{29}$ which in turn may contribute to preterm birth ${ }^{30}$ and $\mathrm{CP}^{11}{ }^{131}$ Advanced maternal age ${ }^{32}$ and assisted reproductive technologies (ARTs) ${ }^{33}$ may also confound the association between multiple birth and $\mathrm{CP}^{34}$

\section{CONCLUSION}

Our study is unique in using reliable observations of multiple births and CP collected over a significant period, thus providing statistical power to detect key trends. Results support reports of an increased risk for $\mathrm{CP}$ in multiples.

Studies linked increased rates of multiples to availability of ARTs and higher maternal age: ${ }^{35-37}$ our findings of increased $\mathrm{CP}$ risk in multiples highlight the importance of limiting the multiple gestation risk of ARTs. ${ }^{33}{ }^{38}$ However, multiples have profited equally from improvements in management of premature births since the 1990s, as indicated by the decrease in CP prevalence among multiples of lower GA or BW.

The continuously higher prevalence of $\mathrm{CP}$ in multiples born at term is, however, of concern. Other studies indicate multiples' increased risk for mortality and severe disability after reaching 38 weeks' gestation ${ }^{815}$ and recommendations acknowledge these risks: for example, NICE guidelines recommend informing women with uncomplicated dichorionic diamniotic and monochorionic diamniotic twin pregnancies about the risks of continuing the pregnancy beyond $37^{+6}$ and $36^{+6}$ weeks, respectively. ${ }^{39}$ More research using population-based studies is needed to investigate the causal mechanisms that link multiple births to increased risk for $\mathrm{CP}^{34}$

\section{Author affiliations}

${ }^{1}$ School of Nursing and Midwifery, Centre for Evidence and Social Innovation, Queen's University Belfast, Belfast, UK

${ }^{2}$ Population Health Sciences Institute, Newcastle University, Newcastle upon Tyne, UK ${ }^{3}$ Norwich Medical School, University of East Anglia, Norwich, UK

${ }^{4}$ University Grenoble Alpes, CNRS, Grenoble INP, CHU Grenoble Alpes, TIMC-IMAG, Grenoble, France

${ }^{5}$ RHEOP, Grenoble, France

${ }^{6}$ Public Health Department; UMR 1027 SPHERE, Universite Toulouse III Paul Sabatier, Toulouse, France

${ }^{7}$ Clinical Epidemiology Unit, University Hospital Centre Toulouse, Toulouse, France

${ }^{8}$ Health Research Institute, University Hospital of Madrid, Madrid, Spain
${ }^{9}$ Department of Paediatric Neurology and Developmental Medicine, University Children's Hospital, Eberhard Karls Universität Tübingen, Tubingen, Germany

${ }^{10}$ Regional Neonatal Unit, Royal Maternity Hospital, Belfast Health and Social Care Trust, Belfast, UK

${ }^{11}$ Department of Obstetrics and Gynecology, Helse More og Romsdal HF, Alesund, Norway

${ }^{12}$ NTNU, Norwegian University of Science and Technology, Trondheim, Norway

Twitter Oliver Perra @oliver_perra and David G Sweet @dsweetbelfast

Acknowledgements We wish to acknowledge the contribution of all SCPE centres and collaborators: the RHEOP, France; RHE31, France; Lavanagh Centre, Cork and Kerry counties, Ireland; CP Register of Western Sweden, Sweden; Eastern Ireland Area CP study, Dublin, Ireland; NPEU, Oxford, UK; The Danish Cerebral Palsy Register Denmark; Central Italy Cerebral Palsy Register, Italy; The Cerebral Palsy Registry of Norway, Norway; ASL, Bologna, Italy; G Gaffney, Galway, Ireland; Madrid Cerebral Palsy Register, Spain; The Northern Ireland Cerebral Palsy Register, Northern Ireland, UK; Slovenian Register of Cerebral Palsy, Slovenia; Programa Vigilancia Nacional da Paralisia Cerbral aos 5 anos, Portugal; Riga Association Rehabilitation Center, Latvia; Cerebral Palsy Register of South-West Hungary, Hungary; Nicosia, Cyprus; Icelandic Cerebral Palsy Register, Iceland; Register of Cerebral Palsy in Tyrol, Austria; Belgian Cerebral Palsy Registry, Belgium; Croatian Cerebral Palsy Register, Croatia; CP register -St Gallen Canton, Switzerland; The Cerebral Palsy Register of Malta, Malta; The Cerebral Palsy Register of Attica-Greece, Greece; Sunderland, Washington, Coalfields and North Easington Cerebral Palsies Register, UK; ISDSHS, Edinburgh, UK; University of Newcastle, Newcastle, UK. This project was completed on behalf of the Surveillance of Cerebral Palsy Europe Network group: A Ego, C Tronc, C Arnaud, M Delobel, V Mc Manus, A Lyons, K Himmelmann M Pahlman, V Dowding, K McConnell, O Perra, J Kurinczuk, G Surman, P Uldall, G Rackauskaite, MG Torrioli, M Marcelli, G L Andersen, S Julsen Hollung, M Bottos, G Gaffney, J de la Cruz, C Pallas, D Neubauer, Anja Radsel, D Virella, M Andrada, A Greitane, K Hollody, I Dakovic, S Sigurdardottir, I Einarsson, K Rostasy, F Zeiner, E Ortibus, I Franki, V Mejaski-Bosnjak, C Kuenzle, A Tscherter, S Attard, A Papavasilou, K Horridge, MJ Platt, I Krägeloh-Mann, V Horber.We also thank the generous contribution and support provided by the Joint Research Centre of the European Commission, and particularly Simona Martin, Agnieszka Kinsner-Ovaskainen and Monica Lanzoni.

Contributors OP designed and conducted the analyses reported in this study and wrote the manuscript. JR contributed significantly to the design of these analyses. JR, MJP, ES, CA, JDLC, IK-M, DGS and SB all contributed significantly to the final draft of this manuscript by discussing results and their interpretations and by revising earlier drafts.

Funding Data reported are collected by the Surveillance of Cerebral Palsy in Europe (SCPE) collaboration. SCPE work was supported by grants from the European Commission (SCPE-NET 200813 07/FIB_H120_FY2014 OG).

Disclaimer The European Commission had no role in study design, data collection, data analysis, data interpretation, or the writing of the report.

Competing interests None declared.

\section{Patient consent for publication Not required.}

Ethics approval The SCPE network has no specific ethical approval as it only gathers anonymised data. Each register had its own ethical approval that follows the legislative rules of its country.

Provenance and peer review Not commissioned; externally peer reviewed.

Data availability statement Data may be obtained from a third party and are not publicly available. Data have been obtained under request to the Joint Research Centre of the European Commission, which manages and provides them on behalf of the Surveillance of Cerebral Palsy in Europe.

Open access This is an open access article distributed in accordance with the Creative Commons Attribution Non Commercial (CC BY-NC 4.0) license, which permits others to distribute, remix, adapt, build upon this work non-commercially, and license their derivative works on different terms, provided the original work is properly cited, appropriate credit is given, any changes made indicated, and the use is non-commercial. See: http://creativecommons.org/licenses/by-nc/4.0/.

\section{REFERENCES}

1 Blondel B, Macfarlane A, Gissler M, et al. Preterm birth and multiple pregnancy in European countries participating in the PERISTAT project. BJOG 2006;113:528-35.

2 Luke B, Martin JA. The rise in multiple births in the United States: who, what, when, where, and why. Clin Obstet Gynecol 2004;47:118-33.

3 Ghosh K. Birth characteristics in England and Wales: 2017. Stat Bull Off Nat/ Stat 2019:1-14.

4 Martin JA, Hamilton BE DP, et al. National Vital Statistics Reports Births : Final Data for 2013. Statistics 2015;64:1-104 
5 Choi SH, Park YS, Shim KS, et al. Recent trends in the incidence of multiple births and its consequences on perinatal problems in Korea. J Korean Med Sci 2010;25:1191-6.

6 Fell DB, Joseph K. Temporal trends in the frequency of twins and higher-order multiple births in Canada and the United States. BMC Pregnancy Childbirth 2012;12:103.

7 Williams K, Hennessy E, Alberman E. Cerebral palsy: effects of twinning, birthweight, and gestational age. Arch Dis Child Fetal Neonatal Ed 1996;75:F178-82.

8 Scher Al, Petterson B, Blair E, et al. The risk of mortality or cerebral palsy in twins: a collaborative population-based study. Pediatr Res 2002:52:671-81.

9 Pharoah PO, Cooke T. Cerebral palsy and multiple births. Arch Dis Child Fetal Neonatal Ed 1996;75:F174-7.

10 Topp M, Huusom LD, Langhoff-Roos J, et al. Multiple birth and cerebral palsy in Europe: a multicenter study. Acta Obstet Gynecol Scand 2004;83:548-53.

11 Trønnes H, Wilcox AJ, Lie RT, et al. Risk of cerebral palsy in relation to pregnancy disorders and preterm birth: a national cohort study. Dev Med Child Neurol 2014;56:779-85.

12 Rosenbaum P, Paneth N, Leviton A, et al. A report: the definition and classification of cerebral palsy April 2006. Dev Med Child Neurol Supp/ 2007;109:8-14.

13 Kinsner-Ovaskainen A, Lanzoni M, Delobel M. Surveillance of cerebral palsy in Europe development of the JRC-SCPE central database and public health indicators. Luxembourg: Publications Office of the European Union, 2017.

14 Cans Cet al. Surveillance of cerebral palsy in Europe: a collaboration of cerebral palsy surveys and registers. Dev Med Child Neurol 2000;42:816-24.

15 Luke B, Keith LG. The contribution of singletons, twins and triplets to low birth weight, infant mortality and handicap in the United States. J Reprod Med 1992;37:661-6.

16 Colver A, Fairhurst C, Pharoah POD. Cerebral palsy. Lancet 2014;383:1240-9.

17 Kiely JL, Kiely M, Blickstein I. Contribution of the rise in multiple births to a potential increase in cerebral palsy. Pediatr Res 2000;47:314A.

18 Sellier E, Platt MJ, Andersen GL, et al. Decreasing prevalence in cerebral palsy: a multi-site European population-based study, 1980 to 2003. Dev Med Child Neurol 2016;58:85-92.

19 WHO. WHO recommendations on interventions to improve preterm birth outcomes, 2019. Available: https://www.who.int/reproductivehealth/publications/maternal perinatal_health/preterm-birth-guideline/en/ [Accessed 25 Sep 2019].

20 Engle WA, American Academy of Pediatrics Committee on Fetus and Newborn. Surfactant-replacement therapy for respiratory distress in the preterm and term neonate. Pediatrics 2008;121:419-32.

21 Nelson KB, Ellenberg JH. Children who "outgrew' cerebral palsy. Pediatrics 1982;69:529-36.

22 Cans C, Dolk H, Platt MJ, et al. Recommendations from the SCPE Collaborative group for defining and classifying cerebral palsy. Dev Med Child Neurol 2007;49:35-8.
23 Cans C, Guillem P, Arnaud C, et al. Prevalence and characteristics of children with cerebral palsy in Europe. Dev Med Child Neurol 2002;44:633-40.

24 Palisano RJ, Gorter JW, Morris C, et al. The creation and purpose of a classification system of children's abilities: Gross Motor Function Classification System (GMFCS). J Intellect Disabil Res 2004;48:346

25 Wood EP, Rosenbaum P. The gross motor function classification system for cerebral palsy: a reliability. Ann Neurol 1998;44:560.

26 Jarvis S, Glinianaia SV, Arnaud C, et al. Case gender and severity in cerebral palsy varies with intrauterine growth. Arch Dis Child 2005;90:474-9.

27 Glinianaia SV, Jarvis S, Topp M, et al. Intrauterine growth and cerebral palsy in twins: a European multicenter study. Twin Res Hum Genet 2006;9:460-6.

28 Topp M, Langhoff-Roos J, Uldall P. Preterm birth and cerebral palsy. predictive value of pregnancy complications, mode of delivery, and Apgar scores. Acta Obstet Gynecol Scand 1997;76:843-8.

29 Lindqvist PG, Happach C. Risk and risk estimation of placental abruption. Eur J Obstet Gynecol Reprod Biol 2006;126:160-4.

30 Ananth CV, Berkowitz GS, Savitz DA, et al. Placental abruption and adverse perinatal outcomes. JAMA 1999;282:1646.

31 Pariente G, Wiznitzer A, Sergienko $R$, et al. Placental abruption: critical analysis of risk factors and perinatal outcomes. J Matern Fetal Neonatal Med 2011;24:698-702.

32 Schneider RE, Ng P, Zhang $X$, et al. The association between maternal age and cerebral palsy risk factors. Pediatr Neurol 2018;82:25-8.

33 Hvidtjørn D, Grove J, Schendel D, et al. Multiplicity and early gestational age contribute to an increased risk of cerebral palsy from assisted conception: a population-based cohort study. Hum Reprod 2010;25:2115-23.

34 Ananth CV, Schisterman EF. Confounding, causality, and confusion: the role of intermediate variables in interpreting observational studies in obstetrics. Am J Obstet Gynecol 2017;217:167-75.

35 Fauser BCJM, Devroey P, Macklon NS. Multiple birth resulting from ovarian stimulation for subfertility treatment. Lancet 2005;365:1807-16.

36 Blondel B, Kaminski M. Trends in the occurrence, determinants, and consequences of multiple births. Semin Perinatol 2002;26:239-49.

37 Reynolds MA, Schieve LA, Martin JA, et al. Trends in multiple births conceived using assisted reproductive technology, United States, 1997-2000. Pediatrics 2003:111:1159-62.

38 Strömberg B, Dahlquist G, Ericson A, et al. Neurological sequelae in children born after in-vitro fertilisation: a population-based study. Lancet 2002:359:461-5.

39 NICE. Overview | Twin and triplet pregnancy | Guidance | NICE, 2019. Available: https://www.nice.org.uk/guidance/ng137/chapter/Recommendations\#timing-of-birth [Accessed 3 Dec 2019]. 